\title{
Oral Nystatin Prophylaxis to Prevent Systemic Fungal Infection in Very Low Birth Weight Preterm Infants : A Randomized Controlled Trial
}

Lily Rundjan ( $\sim$ lily_kartono69@yahoo.co.uk)

Rumah Sakit Dr Cipto Mangunkusumo https://orcid.org/0000-0002-5691-8983

Retno Wahyuningsih

Rumah Sakit Dr Cipto Mangunkusumo

Chrissela Anindita Oeswadi

Rumah Sakit Dr Cipto Mangunkusumo

Miske Marsogi

Rumah Sakit Dr Cipto Mangunkusumo

Ayu Purnamasari

Rumah Sakit Dr Cipto Mangunkusumo

Research article

Keywords: nystatin, fungal colonization, systemic fungal infection

Posted Date: December 10th, 2019

DOI: https://doi.org/10.21203/rs.2.18357/v1

License: (c) (1) This work is licensed under a Creative Commons Attribution 4.0 International License.

Read Full License

Version of Record: A version of this preprint was published at BMC Pediatrics on April 17th, 2020. See the published version at https://doi.org/10.1186/s12887-020-02074-0. 


\section{Abstract}

Background Systemic fungal infection (SFI) is one of leading causes of morbidity and mortality in very low birth weight (VLBW) preterm infants. Because early diagnosis of SFI is challenging due to nonspecific manifestations, prophylaxis becomes crucial. This study aimed to assess effectiveness of oral nystatin as an antifungal prophylaxis to prevent SFI in VLBW preterm infants.

Methods A prospective, open-labelled, randomized controlled trial was performed in a neonatal intensive care unit (NICU) of an academic hospital in Indonesia. Infants with a gestational age $<32$ weeks and/or birth weight of $<1500$ grams with risk factors of fungal infection were assessed for eligibility and randomized to either an intervention group (nystatin) or control group. The intervention group received 1 $\mathrm{ml}$ of oral nystatin three times a day, and the control group received a dose of $1 \mathrm{ml}$ of sterile water three times a day. The incidence of fungal colonization and SFI were observed and evaluated during the sixweek study period. Overall, mortality rates and nystatin-related adverse drug reactions during the study period were also documented.

Results A total of 95 patients were enrolled. The incidence of fungal colonization was lower among infants in nystatin group compared to those in control group $(29.79 \%$ and $56.25 \%$, respectively; relative risk 0.559; $95 \%$ confidence interval 0.357-0.899; $\mathrm{p}$-value=0.009). There were five cases of SFI, all of which were found in the control group ( $p$-value=0.056). There was no difference in overall mortality between the two groups. No adverse drug reactions were noted during the study period.

Conclusions Nystatin is effective and safe as an antifungal prophylactic medication in reducing colonization rates in the study population. Whilst the use of nystatin showed a potential protective effect against SFI among VLBW preterm infants, there was no statistical significant difference in SFI rates between groups.

\section{Background}

Systemic fungal infection (SFI) is a form of late onset neonatal sepsis (LOS) that accounts for $12 \%$ of all LOS among very low birth weight (VLBW) infants (1). The incidence of SFI varies between $1-10 \%$ in VLBW and $2-26 \%$ in extremely low birth weight (ELBW) infants (1-7). In comparison, the incidence of SFI in our hospital was $26 \%$ in VLBW infants between years 2005 and 2008 (8).

Systemic fungal infection is a significant problem in neonatal care due to mortality rates that are comparable with Gram-negative infections, both being 3-4 fold higher than Gram-positive infections (9). Furthermore, SFI is associated with adverse long-term neurodevelopmental outcomes among survivors (2, $3,9-11)$. Prevention of SFI has become crucial because rapid diagnosis of SFI is still challenging. This is due to its nonspecific clinical presentation and low yields of fungal isolation in culture, all of which may result in a delay in instituting treatment $(7,12)$. 
The most common causative agent of SFI is Candida spp. $(1,9,13)$, with $\mathrm{C}$. albicans being the most common vertically transmitted species and C. parapsilosis mostly responsible for horizontal transmission. Other fungal species can occasionally be found in particular condition, such as Malassezia furfur, which has been associated with the use of parenteral lipid nutrition, and Aspergillus spp., which is found predominantly in infants with local skin trauma (14).

Candida spp. is a commensal organism with ability to adhere to human epithelium, particularly in gastrointestinal (GI) tract, leading to colonization [11]. About $88 \%$ of fungal colonizations are detected on the third day after birth, mostly in anus (88.8\%), oral cavity (66.6\%), and umbilicus (55\%) (15). This GI colonization, especially heavy colonization, may become a primary source of translocation through epithelial barriers and systemic dissemination in high-risk VLBW preterm infants due to compromised mucosal integrity or host defences [11-18]. Additional factors that increase the risk factors for fungal colonization and SFI are the presence of central catheters or endotracheal tubes, prolonged use of parenteral nutrition, delayed enteral feeding, and also the use of certain medications such as broad spectrum antibiotics, corticosteroids, theophylline, and histamine type 2 receptor blocker $(1,2,6,16)$.

Prevention of Candida colonization in the GI tract using systemic or oral non-absorbable antifungal prophylaxis has been considered effective in decreasing SFI among high-risk infants (11). A metaanalysis of fluconazole prophylaxis demonstrated a marked reduction in the risk of severe fungal infection in VLBW preterm infants (17). Nevertheless, there have been several reports of emergence of fungal resistance and hepatotoxicity associated with the use of fluconazole $(5,13,18-21)$. A comparable prophylactic effect has also seen with use of oral nystatin, which is not absorbed, allowing sufficient contact with colonizing fungal agents in the GI tract which is the main portal of entry $(22,23)$. Although it is non-toxic, easy to use, and less expensive $(17,18,22-27)$, the validity and applicability of the latest meta-analysis of nystatin prophylaxis (28) were limited due to insufficient data and methodological problems (e.g. concealment, allocation, and blinding problems) $(28,29)$. To date, 14 fluconazole trials were registered compared to five nystatin trials.

In our unit, there has been a documented emergence of Non-albicans Candida (NAC) species (30) with fluconazole resistance occurring in our patient population. Further, we have a limited budget for the provision of medications in our unit, and ongoing difficulties in maintaining intravenous access for systemic antifungal agents. For this reason, we aimed to determine the effectiveness of oral nystatin as an alternative agent for antifungal prophylaxis among VLBW preterm infants in our unit.

\section{Methods}

\section{Study Design}

A prospective, open-labelled, randomized controlled trial was conducted to evaluate the effectiveness of nystatin prophylaxis among preterm and/or VLBW infants. This study was reviewed and approved by the Committee of the Medical Research Ethics of the Faculty of Medicine Universitas Indonesia. This trial has 
been retrospectively registered in clinicaltrials.gov with trial registration number NCT03390374. We adhered CONSORT guideline in reporting this trial results.

\section{Study Setting and Study Population}

This trial was conducted at Cipto Mangunkusumo Hospital, an academic National Hospital in Indonesia, which provides tertiary neonatal care. From 2010 to 2012, eligibility was assessed among all inborn infants admitted to our neonatal intensive care unit within the first 72 hours of life who had a gestational age of $\leq 32$ weeks and/or birth weight of $\leq 1500$ grams and one or more SFI risk factors present (antibiotic therapy, intravenous access, endotracheal tube, orogastric tube, urinary catheter, corticosteroid therapy, parenteral nutrition, and theophylline therapy). All infants suspected of having necrotizing enterocolitis (NEC) within 72 hours after birth, cyanotic congenital heart disease, chromosomal defects, or other critical conditions with poor prognosis were excluded. Written informed consents were obtained prior to recruitment.

\section{Study Intervention}

Enrolled infants were randomly assigned into the nystatin or control groups. Infants in the nystatin group received oral nystatin (Mycostatin® oral suspension $100.000 \mathrm{U} / \mathrm{mL}$, manufactured by Taisho Pharmaceuticals Indonesia) with a dosage of $1 \mathrm{~mL}(0.5 \mathrm{~mL}$ was coated in oral cavity and another $0.5 \mathrm{~mL}$ was given through orogastric tube) three times a day for the six weeks of study period or until no risk factors of SFI was noted. If any sign of GI bleeding was noted, orogastric nystatin administration was suspended and only oral coating with nystatin was continued. Nystatin was discontinued entirely if there was any concern of NEC or shock. The control group received $1 \mathrm{~mL}$ of sterile water three times a day as a coating in oral cavity as according to our protocol of oral hygiene care.

Oropharyngeal and perianal fungal cultures subsequent to direct microscopic examinations were collected weekly to identify GI colonization. These specimens were analyzed in Department of Parasitology, Faculty of Medicine, Universitas Indonesia. In order to diagnose SFI, culture of blood, cerebrospinal fluid (CSF), endotracheal tube aspirate, and urine were done if the patient developed clinical signs of fungal sepsis, fungal meningitis, fungal pneumonia, or fungal urinary tract infections. Once the diagnosis of SFI was established, systemic therapy for fungal infection was commenced using intravenous Amphotericin B. Nystatin was discontinued if the patient no longer had any risk factor for SFI, discharged from the hospital, or died.

\section{Randomization}

Enrollment and randomization were done by co-investigators. Once the parents were consented for the study, co-investigators randomly assigned the infants by using simple randomization method at 1:1 ratio. A sealed opaque envelope was removed from a closed container and opened to determine the group allocation. The allocated treatment regimen was then applied to the infant. Study investigators, attending care teams, and the infants' families were not blinded to treatment allocation.

\section{Study Outcomes}


The primary outcomes of this study were the incidence of fungal colonization and SFI. Weekly oropharyngeal and perianal fungal cultures subsequent to direct microscopic examination were assessed to determine fungal colonization. The result was considered positive if fungal were isolated on either oral or perianal specimens. Colonization was then graded into light ( $<10$ colonies), moderate (10-99 colonies), or heavy (>99 colonies) $(31,32)$. Time of onset of colonization, sites involved, and fungal organism isolated at the colonization site were also documented. Culture results were evaluated if the infants' condition worsened to ascertain whether they met the criteria of SFI. Proven SFI was defined as a positive fungal culture from blood, CSF, endotracheal tube aspirate, deep tissue, or urine $(>10,000$ or more colony-forming unit/mL from sterile bladder catheterization or suprapubic aspiration).

As secondary outcomes, overall mortality rates and nystatin-related adverse drug reactions (such as vomiting, diarrhea, and allergic reaction) during the study period were documented. Fungal-related mortality was defined as mortality that occurred within 72 hours of positive fungal blood culture or positive evidence of disseminated candidiasis on autopsy.

\section{Sample Size and Statistical Analysis}

It was estimated that 35 subjects would be required in each group to detect an absolute $5 \%$ decrease of outcomes among the two groups, with two-tailed a of 0.05 and power of $80 \%$. Data analysis was conducted using an intention-to-treat approach. Baseline data on characteristics and risk factors were reported as descriptive statistics including mean, median, and calculation of dispersion (standard deviation and ranges). Numerical variables were analyzed using independent-sample t-test while categorical variables using either chi-square or fisher's exact test as appropriate. Rate analysis was done with cox regression. The results were considered statistically significant if $p$-value was $<0.05$. Statistical analysis was performed using SPSS software 24.0 for Windows.

\section{Results}

\section{Study Population}

Between October 2010 and November 2012, a total of 123 preterm infants $\leq 32$ weeks' gestational age and/or birth weight of $\leq 1500$ grams were identified. Among these infants, 95 met eligibility criteria and were randomized into either nystatin group $(n=47)$ or control group $(n=48)$ (Fig. 1). Discontinuation of intervention before completion of the proposed observation period (less than three weeks) occurred in 15 infants. However, all these infants were still included in the final analysis. The trial was ended after the length of follow up has been completed. There was no significant difference ( $p$-value $>0.05)$ in baseline neonatal characteristics and risk factors of SFI between the two groups, as shown in Tables 1 and 2, respectively. 
Table 1

Baseline characteristics of subjects

\begin{tabular}{|lll|}
\hline Variables & $\begin{array}{l}\text { Nystatin group } \\
(\mathbf{n}=47)\end{array}$ & $\begin{array}{l}\text { Control group } \\
(\mathbf{n}=\mathbf{4 8})\end{array}$ \\
\hline Gestational age, weeks, mean $( \pm$ SD) & $30.79( \pm 2.04)$ & $30.54( \pm 2.15)$ \\
\hline Gender (Male/Female) & $24 / 23$ & $32 / 16$ \\
\hline Birth weight, gram, mean ( \pm SD) & $1290( \pm 234.58)$ & $1318( \pm 259.16)$ \\
\hline Vaginal delivery, $\mathrm{n}(\%)$ & $30(53.2)$ & $25(62.5)$ \\
\hline Apgar score at 5 min, mean $( \pm$ SD) & $8.23( \pm 1.29)$ & $7.44( \pm 1.49)$ \\
\hline Rupture of membranes $>24$ hrs, $n(\%)$ & $10(21.2)$ & $7(14.6)$ \\
\hline
\end{tabular}


Table 2

Risk factors of systemic fungal infection

\begin{tabular}{|c|c|c|c|}
\hline \multirow[t]{2}{*}{ Variables } & Nystatin group & Control group & p-value \\
\hline & $(n=47)$ & $(n=48)$ & \\
\hline \multicolumn{4}{|l|}{ Duration of stay in NICU, $\mathrm{n}(\%)$} \\
\hline Mean duration time, days, mean $( \pm S D)$ & $9.81( \pm 14.94)$ & $13.64( \pm 15.53)$ & 0.23 \\
\hline$<7$ days, $\mathrm{n}(\%)$ & $8(17.02)$ & $8(16.67)$ & 0.16 \\
\hline > 7 days, $\mathrm{n}(\%)$ & $18(38.3)$ & $27(56.25)$ & \\
\hline Use of peripheral venous access, $n(\%)$ & $47(100)$ & $48(100)$ & 1.00 \\
\hline Duration of peripheral venous access (days) & $24(6-42)$ & $28(5-62)$ & 0.18 \\
\hline Use of central venous access, $\mathrm{n}(\%)$ & $38(80.9)$ & $37(77.1)$ & 0.80 \\
\hline Duration of central venous access (days) & $19(0-42)$ & $19(0-42)$ & 0.96 \\
\hline Use of orogastric tube, $n(\%)$ & $47(100)$ & $47(97.9)$ & 1.00 \\
\hline Duration of orogastric tube, median (days) & $30(8-42)$ & $30(8-42)$ & 0.76 \\
\hline Use of endotracheal tube, $n(\%)$ & $10(21.28)$ & $16(33.33)$ & 0.19 \\
\hline Duration of endotracheal tube (days) & $2.6(0-21)$ & $4.29(0-31)$ & 0.26 \\
\hline Use of antibiotic therapy, $\mathrm{n}(\%)$ & $43(91.5)$ & $46(95.8)$ & 0.44 \\
\hline Duration of antibiotic therapy (days) & $19(0-42)$ & $21(0-42)$ & 0.4 \\
\hline Use of aminophylline, $\mathrm{n}(\%)$ & $28(59.6)$ & $35(72.9)$ & 0.17 \\
\hline Duration (days) & $11(1-42)$ & $13(3-42)$ & 0.42 \\
\hline Use of steroid, $\mathrm{n}(\%)$ & $3(6.38)$ & $3(6.25)$ & 0.65 \\
\hline Duration (days) & $1(0-12)$ & $1(0-3)$ & 0.38 \\
\hline Use of parenteral nutrition, $\mathrm{n}(\%)$ & $45(95.7)$ & $47(97.9)$ & 0.62 \\
\hline Duration (days) & $21(0-41)$ & $22(0-42)$ & 0.53 \\
\hline Duration of parenteral lipid (days) & $16(0-40)$ & $19(4-39)$ & 0.15 \\
\hline
\end{tabular}

\section{Fungal Colonization}

Data on fungal colonization, SFI, and mortality are presented in Table 3. The absolute fungal colonization rate was $26 \%$ lower among infants in nystatin group (29.79\%) as compared to those in control group 
(56.25\%) (RR 0.56; 95\% $\mathrm{Cl} 0.36-0.90, \mathrm{p}$-value $=0.009)$. The colonization rate was highest in the first and second week of life (Fig. 2), but the mean age of first documented colonization was similar between the two groups ( 11 vs 10 days, $p>0.05$ ). Overtime, colonization rates during six-week observation differed significantly between the two groups ( $p$-value $=0.01$ ). Significantly lower rates of fungal colonization were seen after 14 days of intervention (Hazard Ratio $=0.475 ; 95 \% \mathrm{Cl} 0.249-0.909, \mathrm{p}$-value $=0.006$ ) with a number needed to treat of four.

Table 3

Fungal colonization, systemic fungal infection, and mortality

\begin{tabular}{|c|c|c|c|c|c|}
\hline \multirow{2}{*}{\multicolumn{2}{|c|}{$\begin{array}{l}\text { Variable } \begin{array}{l}\text { Nystatin Group } \\
(n=47)\end{array} \\
\text { Fungal colonization, } n(\%)\end{array}$}} & \multirow[b]{2}{*}{$14(29.79)$} & \multirow{2}{*}{$\begin{array}{l}\text { Control Group }(\mathbf{n}=\mathbf{4 8}) \\
\qquad 27(56.25)\end{array}$} & \multirow{2}{*}{ 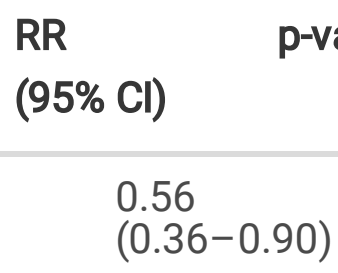 } & -value \\
\hline & & & & & 0.009 \\
\hline \multicolumn{6}{|c|}{ Colonization site(s) } \\
\hline $\begin{array}{l}\text { Singl } \\
(\%)\end{array}$ & site colonization, $\mathrm{n}$ & $11(23.40)$ & $12(25.00)$ & $\begin{array}{l}0.78(0.49- \\
1.26)\end{array}$ & 0.281 \\
\hline $\begin{array}{l}\text { Multi } \\
\text { color }\end{array}$ & $\begin{array}{l}\text { le sites } \\
\text { zation, } n(\%)\end{array}$ & $3(6.38)$ & $15(31.25)$ & $\begin{array}{l}0.55(0.37- \\
0.72)\end{array}$ & 0.001 \\
\hline \multicolumn{6}{|c|}{ Colonization grade } \\
\hline Light & colonization, n (\%) & $5(10.64)$ & $7(14.58)$ & reference & \\
\hline $\begin{array}{l}\text { Modt } \\
(\%)\end{array}$ & rate colonization, n & $3(6.38)$ & $5(10.42)$ & $\begin{array}{l}0.93(0.46- \\
1.92)\end{array}$ & 1.000 \\
\hline Heav & colonization, n (\%) & $6(12.77)$ & 15 (31.25) & $\begin{array}{l}0.82(0.47- \\
1.42)\end{array}$ & 0.471 \\
\hline $\begin{array}{l}\text { Systemic } \\
(\%)\end{array}$ & Eungal Infection, n & $0(0)$ & $5(10.4)$ & $\begin{array}{l}0.09(0.01- \\
1.63)\end{array}$ & 0.056 \\
\hline Prior & colonization, n/total & - & $4 / 5$ & & 0.130 \\
\hline $\begin{array}{l}\text { Multi } \\
\text { n/tot }\end{array}$ & le site colonization, & - & $2 / 5$ & & 0.053 \\
\hline \multicolumn{6}{|l|}{ Mortality } \\
\hline Overall $\mathrm{m}$ & rtality, n (\%) & $7(14.9)$ & $9(18.8)$ & $\begin{array}{l}0.86(0.48- \\
1.57)\end{array}$ & 0.616 \\
\hline Fungal-re & ated mortality, n (\%) & 0 & 0 & & \\
\hline
\end{tabular}

The number of infants with single site colonization was not significantly different between the two groups (11 vs 12 infants, $p$-value $=0.281$ ). However, the incidence of multiple site colonization was significantly lower in the nystatin group (three infants; $6 \%$ ) as compared to the control group (15 infants; 
$31 \%)(p$-value $=0.001)$. There were fewer infants with heavy colonization in nystatin group compared to those in control group, although this did not reach statistical significance.

The fungal species did not differ significantly between both groups. The most common isolated fungal species was C. albicans (39\%). In relation to multiple species colonization, there were three infants simultaneously colonized by three different fungal species (C. albicans, C. parapsilosis and C. kefyr or C. tropicalis) and one infant colonized with 4 fungal species simultaneously (C. albicans, C. tropicalis, C. glabrata, and Malassezia spp. All these four infants were in the control group. Most of heavy colonization cases in the control group (53.3\%) were caused by multiple species, whereas all cases with heavy colonization in the nystatin group were only caused by a single species (C. albicans).

Table 4

Fungal species on colonization

\begin{tabular}{|c|c|c|c|}
\hline & $\begin{array}{l}\text { Nystatin group } \\
(n=14)\end{array}$ & $\begin{array}{l}\text { Control group } \\
(n=27)\end{array}$ & p-value \\
\hline Single species, n (\%) & $11(78.57)$ & $17(62.96)$ & $0.481^{a}$ \\
\hline Candida albicans & 7 & 9 & \\
\hline Candida non albicans* & 2 & 7 & \\
\hline Malassezia, spp & 2 & 1 & \\
\hline Multiple species, $\mathrm{n}(\%)^{\star \star}$ & $3(21.43)$ & $10(37.04)$ & \\
\hline \multicolumn{4}{|c|}{${ }^{\star}$ C. parapsilosis/glabrata/tropicalis } \\
\hline \multicolumn{4}{|c|}{${ }^{\star \star}$ C. albicans with C. parapsilosis/glabrata/tropicalis/kefyr or Malassezia spp. } \\
\hline \multicolumn{4}{|c|}{${ }^{\mathrm{a}}$ Calculated as comparison between single and multiple species } \\
\hline
\end{tabular}

\section{Systemic Fungal Infection}

During the study period there were five cases of SFI. All of them occurred in the control group but the differing incidence did not reach statistical significance as compared to the nystatin group (absolute risk reduction of $10.42 \%$, p-value $=0.056$ ). These cases were diagnosed by positive blood culture (three cases), positive blood and urine culture (one case), and positive intestinal tissue culture from a surgical NEC patient (one case). With respect to prior colonization, four SFI cases were preceded by colonization with the same fungal species, either light (one case) or heavy colonization (three cases), and one case was not preceded by colonization at all. There were two cases noted as having multiple site colonization prior to the development of SFI. The fungal organisms causing SFI were C. albicans (three cases), C. krusei (one case), and C. tropicalis (one case). These organisms were detected at a median age of 18 days (range $8-37$ days).

\section{Secondary Outcomes}


The overall mortality was similar between both groups (14.9\% in nystatin group and $18.8 \%$ in control group, $p$-value $=0.616$ ), but none of the deaths were related to fungal infection. Furthermore, there was no reported nystatin-related adverse drug reaction during the study period.

\section{Discussion}

This randomized controlled trial demonstrates that oral nystatin significantly reduced the incidence of fungal colonization in our neonatal unit. Although no cases of SFI occurred in the nystatin group, the difference in SFI rates between the two groups did not reach statistical difference.

A number of risk factors have been reported to be associated with an increased risk of developing SFI. Preceding colonization, particularly in GI tract and skin, is consistently recognized as the most important predictor of SFI $(20,21,33-35)$. High rates of colonization (ranging between 22-87\%) have been noted among preterm and VLBW infants who do not receive any antifungal prophylaxis $(18,23,25,27,34,36)$. A similar result has been found in our study, with the colonization rate in the control group being $56.3 \%$, as compared to a $29.8 \%$ rate in the nystatin group. Density and number of colonization sites reported have a positive correlation to the risk of subsequent SFI development $(21,37)$, thereby increasing the risk of fungal translocation and dissemination $(21,38)$. Other studies have reported that high fungal densities and multiple fungal colonization sites are associated with greater SFI risk. Kaufman, et al demonstrated that the risk of SFI increased with each additional site colonized (odds ratio 3.0; 95\% confidence interval 1.4 to 6.8). The same fungal species are mostly documented in both the infection and colonization sites $(34,39,40)$. These results are similar to those reported in our study. Four of five cases in the control group were preceded by either heavy or multiple site colonization with similar fungal species. The exception was the one SFI that occurred without evidence of prior colonization.

Nystatin is a well-studied polyene antifungal that has a comparable efficacy with fluconazole for SFI prophylaxis amongst preterm and/or VLBW infants $(18,22,41)$. Previous studies have proven that nystatin can prevent the development of colonization and SFI $(18,25,27)$. A meta-analysis demonstrated that one in every 4-9 infants was prevented from developing SFI after receiving either fluconazole or nystatin prophylaxis (29). Our study demonstrated a statistically significant lower rate of fungal colonization by $26 \%$ in the nystatin group as compared to the control group. All five SFI cases in our study were in control group and no SFI incidence found in nystatin group. Although the difference in SFI incidence between both groups was not statistically significant, this result has suggested a declining trend of SFI risk and potential preventive effect of nystatin prophylaxis against SFI. We observed that incidence of SFI in our current study (5.2\%) was much lower than our previous rate in the epoch of 20052008 (26\%) (8). This large difference in incidence of SFI may have been influenced by a recent change in our clinical practice with the implementation of restrictive of antibiotic guidelines (narrow spectrum of antibiotics) since 2008 .

The most common fungal organism cultured in this study was C. albicans, a finding similar to that of previous studies $(23,25,42)$. Although $\mathrm{C}$. albicans was still the most frequently encountered fungal 
organism, the occurrence of NAC species (consisting of C. parapsilosis, C. tropicalis, C. glabrata, C. krusei, and C. kefyr) continues to increase. The shift from C. albicans to NAC species in our unit has been previously reported by Wahyuningsih et al (30). This effect may be due to long-term extensive use of fluconazole when Amphotericin B was not available during that epoch. The notable increase in the incidence of NAC may become an important determinant in selecting a prophylactic drug because some NAC species, particularly C. glabrata and C. krusei, have been reported to be natively resistant to fluconazole $(21,43,44)$. In contrast, nystatin is efficacious against all Candida species and no resistance has been documented with its use. Malassezia spp. was also found in our study. Prematurity, low birth weight, use of parenteral nutrition with lipid emulsion, use of central venous catheters, and contact with healthcare staff with contaminated hands were related to Malassezia spp. colonization in infants. There were some studies which have reported that this organism is an important cause of SFI and have demonstrated reduced susceptibility to fluconazole and flucytosine. To date, there are no reports of Malassezia spp. resistance to nystatin (45-48).

Based on the findings of the current study and previous studies, it is more difficult to reduce the risk of SFI once colonization has occurred $(15,23,39,43,49)$. Currently, there is no established guidelines regarding the most effective timing and duration in using nystatin prophylaxis among high-risk infants. Several previous studies suggested that colonization may start within $3-6$ days of life $(15,23,35,50)$. Therefore, to be effective in preventing fungal overgrowth and infection, oral nystatin should be commenced before the onset of colonization, particularly within the first 72 hours of life $(23,49)$. In contrast, the mean age of first colonization in our study was 10-11 days, longer than reported in the other previous studies. Most studies administered antifungal prophylaxis until patients were not in intensive care or no longer experiencing any risk factors for fungal infections. Although risk factors in every unit may be different, previous studies mostly agreed that antifungal prophylaxis administration for four to six weeks was safe and resulted in lower risk of colonization $(5,35,38)$.

No mortality attributable to fungal infection was reported in any of our SFI cases. However, further study is still required to specifically evaluate the effect of nystatin on fungal-related mortality and long-term outcome. Oral nystatin is not absorbed, hence it is unlikely that systemic adverse reactions would be expected from this drug. The few adverse effects that were previously reported among children and adults, such as vomiting, diarrhea, and allergic reaction $(5,21,51)$ were not found in our study.

\section{Study Limitations and Further Suggestions}

To date, this study is the first randomized controlled trial in our nation assessing the effectiveness of nystatin prophylaxis in preterm VLBW infants. In our study, no newborn infants under 28 weeks' gestational age were recruited due to low survival related to limited resources in our NICU during the study period. Further study is required to assess the effect of nystatin prophylaxis in this particular gestational age group. 
In the setting of a unit with high SFI incidence, this study has shown that nystatin prophylaxis is effective in preventing colonization and can potentially decrease the risk of SFI. Since some neonatal centers in Indonesia still face financial limitations and difficulties in maintaining intravenous access for systemic antifungal prophylaxis, the outcomes of this study have potential significance in enhancing clinicians understanding about the possible benefits of using nystatin as an alternative agent for fungal prophylaxis in a neonatal intensive care setting in Indonesia.

\section{Conclusion}

Nystatin appears to be an effective and safe alternative prophylactic antifungal medication that reduces fungal colonization. Although reduced infection rates did not reach statistical significance, nystatin prophylaxis demonstrated a potential protective effect against SFI among VLBW preterm infants. Further studies are still required to assess the efficacy of nystatin prophylaxis among newborns under 28 weeks' gestational age.

\section{List Of Abbreviations}

CSF: cerebrospinal fluid; ELBW: extremely low birth weight; GI: gastrointestinal; LOS: late onset sepsis; NAC: Non-albicans Candida; NEC: necrotizing enterocolitis; NICU: neonatal intensive care unit; SFI: systemic fungal infection; VLBW: very low birth weight

\section{Declarations}

\section{Ethics approval and consent to participate}

This study was reviewed and approved by the Committee of the Medical Research Ethics of the Faculty of Medicine Universitas Indonesia. Ethical aspect of research was followed very strictly and written informed consent was obtained prior to study enrolment. Confidentiality of the subjects was maintained to ensure privacy of their data. Codes were used to anonymize the identity of subjects.

\section{Consent for publication}

Not applicable.

\section{Availability of data and material}

All data generated or analyzed during the current study are included in this article. 


\section{Competing interest}

The authors declare that they have no competing interests.

\section{Funding}

None.

\section{Authors' contributions}

LR and RW designed the study. CAO participated in data collection. LR, CAO, MM, and AP carried out statistical analysis, reviewed and revised the manuscript. All the authors read and approved the final manuscript.

\section{Acknowledgements}

The authors would like to express their sincere gratitude for Anissa Nur Aini, M.D., Citra Ganesha, M.D., Sri Sunarti, and all NICU nurses of Cipto Mangunkusumo Hospital, Jakarta for their participations in this research.

\section{References}

1. Stoll BJ, Hansen N, Fanaroff AA, Wright LL, Carlo WA, Ehrenkranz RA, et al. Late-onset sepsis in very low birth weight neonates: the experience of the NICHD Neonatal Research Network. Pediatrics. 2002;110(2 Pt 1):285-91.

2. Barton M, O'Brien K, Robinson JL, Davies DH, Simpson K, Asztalos E, et al. Invasive candidiasis in low birth weight preterm infants: risk factors, clinical course and outcome in a prospective multicenter study of cases and their matched controls. BMC Infect Dis. 2014;14:327.

3. Benjamin DK, Jr., Stoll BJ, Fanaroff AA, McDonald SA, Oh W, Higgins RD, et al. Neonatal candidiasis among extremely low birth weight infants: risk factors, mortality rates, and neurodevelopmental outcomes at 18 to 22 months. Pediatrics. 2006;117(1):84-92.

4. Cabrera C, Frank M, Carter D, Bhatia J. Fluconazole prophylaxis against systemic candidiasis after colonization: a randomized, double-blinded study. J Perinatol. 2002;22:604.

5. Kicklighter SD, Springer SC, Cox T, Hulsey TC, Turner RB. Fluconazole for prophylaxis against candidal rectal colonization in the very low birth weight infant. Pediatrics. 2001;107(2):293-8.

6. Roilides E. Invasive candidiasis in neonates and children. Early Hum Dev. 2011;87 Suppl 1:S75-6. 
7. Greenberg RG, Benjamin DK, Jr. Neonatal candidiasis: diagnosis, prevention, and treatment. J Infect. 2014;69 Suppl 1:S19-22.

8. Wijayanto D, Amir I, Wahyuningsih R, Windiastuti E. Prevalens dan sebaran faktor risiko mikosis sistemik pada neonatus dengan sepsis awitan lambat di RS Dr Cipto Mangunkusumo (Prevalence and risk factors of systemic fungal infection among neonates with late-onset sepsis in Cipto Mangunkusumo Hospital). Sari Pediatri. 2009;11(4):229-37.

9. Makhoul IR, Sujov P, Smolkin T, Lusky A, Reichman B. Epidemiological, clinical, and microbiological characteristics of late-onset sepsis among very low birth weight infants in Israel: a national survey. Pediatrics. 2002;109(1):34-9.

10. Adams-Chapman I, Bann CM, Das A, Goldberg RN, Stoll BJ, Walsh MC, et al. Neurodevelopmental outcome of extremely low birth weight infants with Candida infection. J Pediatr. 2013;163(4):961-7 e3.

11. Stoll BJ, Hansen NI, Adams-Chapman I, Fanaroff AA, Hintz SR, Vohr B, et al. Neurodevelopmental and growth impairment among extremely low-birth-weight infants with neonatal infection. Jama. 2004;292(19):2357-65.

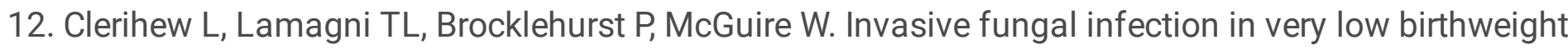
infants: national prospective surveillance study. Arch Dis Child Fetal Neonatal Ed. 2006;91(3):F18892.

13. Brecht $M$, Clerihew $L$, McGuire W. Prevention and treatment of invasive fungal infection in very low birthweight infants. Arch Dis Child Fetal Neonatal Ed. 2009;94(1):F65-9.

14. Castagnola E, Faraci M, Fioredda F, Amoroso L, Risso F, Franceschi A, et al. Invasive mould infections in newborns and children. Early Hum Dev. 2011;87 Suppl 1:S67-9.

15. Ali GY, Algohary EH, Rashed KA, Almoghanum M, Khalifa AA. Prevalence of Candida colonization in preterm newborns and VLBW in neonatal intensive care unit: role of maternal colonization as a risk factor in transmission of disease. J Matern Fetal Neonatal Med. 2012;25(6):789-95.

16. Filioti J, Spiroglou K, Roilides E. Invasive candidiasis in pediatric intensive care patients: epidemiology, risk factors, management, and outcome. Intensive Care Med. 2007;33(7):1272-83.

17. Austin N, Cleminson J, Darlow BA, McGuire W. Prophylactic oral/topical non-absorbed antifungal agents to prevent invasive fungal infection in very low birth weight infants. Cochrane Database Syst Rev. 2015(10):CD003478.

18. Aydemir C, Oguz SS, Dizdar EA, Akar M, Sarikabadayi YU, Saygan S, et al. Randomised controlled trial of prophylactic fluconazole versus nystatin for the prevention of fungal colonisation and invasive fungal infection in very low birth weight infants. Arch Dis Child Fetal Neonatal Ed. 2011;96(3):F164-8.

19. Isaacs D. Fungal prophylaxis in very low birth weight neonates: nystatin, fluconazole or nothing? Curr Opin Infect Dis. 2008;21(3):246-50.

20. Manzoni P, Farina D, Leonessa M, d'Oulx EA, Galletto P, Mostert M, et al. Risk factors for progression to invasive fungal infection in preterm neonates with fungal colonization. Pediatrics. 2006;118(6):2359-64. 
21. Manzoni P, Farina D, Galletto P, Leonessa M, Priolo C, Arisio R, et al. Type and number of sites colonized by fungi and risk of progression to invasive fungal infection in preterm neonates in neonatal intensive care unit. J Perinat Med. 2007;35(3):220-6.

22. Mersal A, Alzahrani I, Azzouz M, Alsubhi A, Alsawaigh H, Albshri N, et al. Oral Nystatin Versus Intravenous Fluconazole as Neonatal Antifungal Prophylaxis: Non-inferiority Trial. J Clin Neonatol. 2013;2(2):88-92.

23. Ozturk MA, Gunes T, Koklu E, Cetin N, Koc N. Oral nystatin prophylaxis to prevent invasive candidiasis in Neonatal Intensive Care Unit. Mycoses. 2006;49(6):484-92.

24. Blyth CC, Barzi F, Hale K, Isaacs D. Chemoprophylaxis of neonatal fungal infections in very low birthweight infants: efficacy and safety of fluconazole and nystatin. J Paediatr Child Health. 2012;48(9):846-51.

25. Ganesan K, Harigopal S, Neal T, Yoxall CW. Prophylactic oral nystatin for preterm babies under 33 weeks' gestation decreases fungal colonisation and invasive fungaemia. Arch Dis Child Fetal Neonatal Ed. 2009;94(4):F275-8.

26. Shane AL, Stoll BJ. Recent developments and current issues in the epidemiology, diagnosis, and management of bacterial and fungal neonatal sepsis. Am J Perinatol. 2013;30(2):131-41.

27. Sims ME, Yoo Y, You H, Salminen C, Walther FJ. Prophylactic oral nystatin and fungal infections in very-low-birthweight infants. Am J Perinatol. 1988;5(1):33-6.

28. Cleminson J, Austin N, McGuire W. Prophylactic systemic antifungal agents to prevent mortality and morbidity in very low birth weight infants. Cochrane Database Syst Rev. 2015(10):CD003850.

29. Austin N, Darlow BA, McGuire W. Prophylactic oral/topical non-absorbed antifungal agents to prevent invasive fungal infection in very low birth weight infants. Cochrane Database Syst Rev. 2009(4):CD003478.

30. Wahyuningsih R RA, El-Jannah SM, Amir I, Prihartono J. Kandidemia pada neonatus yang mengalami kegagalan terapi antibiotik (Candidemia among neonates with antibiotic therapy failure). Maj Kedok Indon. 2008;58(4):110-5.

31. Lau AF, Kabir M, Chen SC, Playford EG, Marriott DJ, Jones M, et al. Candida colonization as a risk marker for invasive candidiasis in mixed medical-surgical intensive care units: development and evaluation of a simple, standard protocol. J Clin Microbiol. 2015;53(4):1324-30.

32. White DJ, Vanthuyne A. Vulvovaginal candidiasis. Sex Transm Infect. 2006;82 Suppl 4:iv28-30.

33. Bendel CM. Colonization and epithelial adhesion in the pathogenesis of neonatal candidiasis. Semin Perinatol. 2003;27(5):357-64.

34. Huang YC, Su LH, Wu TL, Lin TY. Genotyping analysis of colonizing candidal isolates from very-lowbirthweight infants in a neonatal intensive care unit. J Hosp Infect. 2004;58(3):200-3.

35. Kaufman DA, Gurka MJ, Hazen KC, Boyle R, Robinson M, Grossman LB. Patterns of fungal colonization in preterm infants weighing less than 1000 grams at birth. Pediatr Infect Dis $\mathrm{J}$. 2006;25(8):733-7. 
36. Manzoni P, Arisio R, Mostert M, Leonessa M, Farina D, Latino MA, et al. Prophylactic fluconazole is effective in preventing fungal colonization and fungal systemic infections in preterm neonates: a single-center, 6-year, retrospective cohort study. Pediatrics. 2006;117(1):e22-32.

37. Pappu-Katikaneni LD, Rao KP, Banister E. Gastrointestinal colonization with yeast species and Candida septicemia in very low birth weight infants. Mycoses. 1990;33(1):20-3.

38. Kaufman D, Boyle R, Hazen KC, Patrie JT, Robinson M, Donowitz LG. Fluconazole prophylaxis against fungal colonization and infection in preterm infants. N Engl J Med. 2001;345(23):1660-6.

39. El-Masry FA, Neal TJ, Subhedar NV. Risk factors for invasive fungal infection in neonates. Acta Paediatr. 2002;91(2):198-202.

40. Reagan DR, Pfaller MA, Hollis RJ, Wenzel RP. Characterization of the sequence of colonization and nosocomial candidemia using DNA fingerprinting and a DNA probe. J Clin Microbiol. 1990;28(12):2733-8.

41. Violaris K, Carbone T, Bateman D, Olawepo O, Doraiswamy B, LaCorte M. Comparison of fluconazole and nystatin oral suspensions for prophylaxis of systemic fungal infection in very low birthweight infants. Am J Perinatol. 2010;27(1):73-8.

42. Howell A, Isaacs D, Halliday R, Australasian Study Group For Neonatal I. Oral nystatin prophylaxis and neonatal fungal infections. Arch Dis Child Fetal Neonatal Ed. 2009;94(6):F429-33.

43. Leibovitz E. Strategies for the prevention of neonatal candidiasis. Pediatr Neonatol. 2012;53(2):83-9.

44. Rowen JL, Tate JM, Nordoff N, Passarell L, McGinnis MR. Candida isolates from neonates: frequency of misidentification and reduced fluconazole susceptibility. J Clin Microbiol. 1999;37(11):3735-7.

45. Al-Sweih N, Ahmad S, Joseph L, Khan S, Khan Z. Malassezia pachydermatis fungemia in a preterm neonate resistant to fluconazole and flucytosine. Medical mycology case reports. 2014;5:9-11.

46. Chryssanthou E, Broberger U, Petrini B. Malassezia pachydermatis fungaemia in a neonatal intensive care unit. Acta Paediatr. 2001;90(3):323-7.

47. Welbel SF, McNeil MM, Pramanik A, Silberman R, Oberle AD, Midgley G, et al. Nosocomial Malassezia pachydermatis bloodstream infections in a neonatal intensive care unit. Pediatr Infect Dis J. $1994 ; 13(2): 104-8$.

48. Gross GJ, Macdonald NE, Mackenzie AM. Neonatal rectal colonization with Malassezia furfur. Can J Infect Dis. 1992;3(1):9-13.

49. Faix RG, Kovarik SM, Shaw TR, Johnson RV. Mucocutaneous and invasive candidiasis among very low birth weight (less than 1,500 grams) infants in intensive care nurseries: a prospective study. Pediatrics. 1989;83(1):101-7.

50. Baley JE, Kliegman RM, Boxerbaum B, Fanaroff AA. Fungal colonization in the very low birth weight infant. Pediatrics. 1986;78(2):225-32.

51. Aghai ZH, Mudduluru M, Nakhla TA, Amendolia B, Longo D, Kemble N, et al. Fluconazole prophylaxis in extremely low birth weight infants: association with cholestasis. J Perinatol. 2006;26(9):550-5. 